\title{
Precise voltage control, power sharing for DC-bus with hybrid energy storage and (Neuro-Fuzzy) controller based MPPT for Hybrid Renewable Energy
}

\author{
Fadhil Abbas Mahdi Al-Qrimli \\ College of Engineering, Uruk University. Baghdad. Iraq.
}

dr.fadhil_alqrimli@uruk.edu.iq

\begin{abstract}
The main objective of this work is to design and simulation of the stand-alone Hybrid Renewable Energy system (HRES), separated from the main local network, the effect of super capacitors when connected to the system, and the effect of power source control system on the response and work of super capacitors. It consists of Photovoltaic, Wind turbine, Hybrid Energy Storage System (HESS). The HESS system consists of Batteries, Supper capacitors, with chargers. The proposed system used real record of weather pattern and load conditions for Al-Mahmoudiya Hospital. The variable sources are changing with different weather conditions. Being important energy sources for generating electricity directly from the sun. In order to generate electrical energy that is sustainable and reliable, highly efficient, low cost, and continuous. It can provide maximum power use. The absence of winds in most regions of Iraq permanently led to the use of such a type of renewable energy (RE) system called solar updraft tower (SUT). The wind turbine can be fixed inside the chimney of the SUT, to make the turbine run smoothly and continuously. Each of the HRES parts is controlled by a converter specific to each source due to the nature of the nonlinear source work. In this paper, the main sources of energy are photovoltaic panels and SUT. Finally, MATLAB program using real recorded data, the system work at a high efficiency of $98 \%$. So, the simulation results show the HRES system have excellent results and fast tracking to supply the load demand.
\end{abstract}

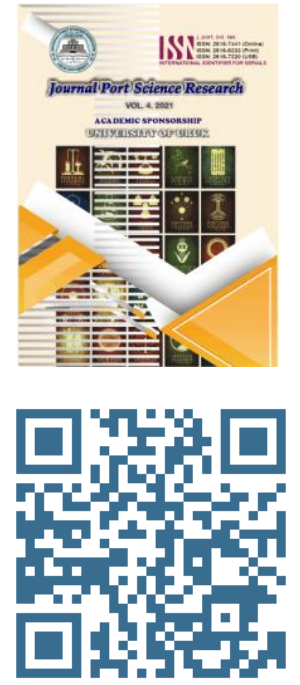

Crossref

10.36371/port.2021.2.4

Keywords: Renewable energy, solar updraft tower, DFIG, PI controller, vector controller, MATLAB/Simulink.

\section{INTRODUCTION}

Renewable Energy (RE) sources are among the sources that have attracted the attention of researchers all over the world in the recent years because of their wide importance in the field of energy. It is characterized by being clean, environmentally friendly. It is also one of the sources that does not deplete with time, with long life span and less cost. It is generally used in areas that are far from the local network, and it is also used separately or connected with the local network to reduce the loads connected to grid. As well as to reduce the use of diesel generators that have been used due to interruptions in the local network. Especially in government institutions and residential areas, which are not environmental and produce polluted gases, and the price of diesel is also rising. Therefore, it is better to use renewable energy sources because they are cost-effective, environmentally friendly and not implemented over time [1, 2]. Example power from solar panels and wind power, hydropower. The main goal of designing a RE system that contains more than one diverse sources. It is more reliable and more efficient, supply to the load, than a system contains one renewable energy source, under varying weather condition, with minimum cost [2, 3, 4]. A HRE system is designed for at least 20 years of operation. When designing a system that contains hybrid renewable energy sources are separated from the local network. This is in order to ensure the reliability and high efficiency of the system. The energy storage system (batteries) must be used and it has an important role to supply the loads. In some types of HRESS with the use of batteries, the remaining power from the solar panels and wind turbines after supply the loads is used for the purpose of charging the batteries only. This is through the charging regulator and the batteries feed the required loads in the evening period due to the lack of suitable ambient conditions for the operation of the sources, and during long emergency interruptions which occur during the work of the RE sources during the day. The supper capacitors also have been used in the system to solve the problems of the current and voltage transient. It is characterized by being fast charging and discharging and making use of the energy that is charged, when it is needed in the system, as well as preserving the life of the batteries from starting discharging current, and the remaining power can be stored in after charging the batteries [5]. Thus, the system is more reliable, less expensive and highly efficient. In the paper, given that winds are not present in most regions of Iraq, especially in Baghdad, based on meteorological data measured by special devices from the Ministry of Science and Technology. The SUT is used in this paper, which relies on solar irradiance, as a form of RE. It was used and the concept 
was initially put forward by which is based on the use of solar chimney power (SCP) technology in energy production. In some conferences and research, Professor Schleicher has replicated the concept and designed a prototype of SCP in the Manzanares area of Ciudad Real 150 kilometers south of Madrid, Spain [6]. The plant power was more than $95 \%$ of the rated power [7]. Iraq is one of the countries, which have good levels of solar radiation. As the speed of the warm air is produced, which rotates the wind turbine due to the difference between the temperature inside and outside the collector, the collector is part of the SUT, and the power provided by the generator connected with the wind turbine depends on the collector area and the tower height, as shown in Fig 1.1. It also has another advantage, which is the thermal energy storage materials (Water tubes are filled with black material and paraffin wax) $[6,8]$, inside the collector, as it works with batteries to supply the loads in the evening period, and this leads to a reduction in the number of batteries used and thus a lower cost.

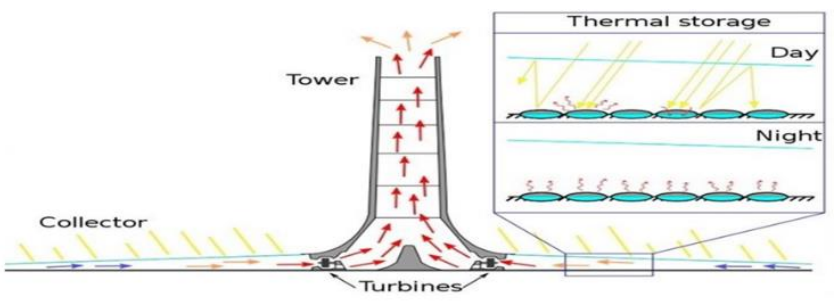

Fig.1.1 The working principle of the updraft tower with the thermal storage working as a heat sink [6].

From the literature review there are main problems, first part which is (how to enhance the overall performance of the PV power system using an effective MPPT technology?). Therefore, this work uses a suitable combination of various intelligent techniques, such as the FLC and ANN predictive (regression) and comparison with FLC and the conventional (P\&O) technique. To verify the efficiency of different MPPT algorithms at various external requested weather conditions for the designed system. Second part as for the reasons for choosing the DFIG, because it has advantages. The most important of these features, using DFIG is controlling (25$30) \%$ of the total power of power electronics converters, which is reducing the cost of these converters. As well as to enhance the performance of the ac mains network and its power factor (p.f.). The voltage and frequency of the stator windings are constant regardless of the speed change of the wind turbine. Finally, modeling and simulation of all renewable energy sources, with its controller in the MATLAB program. For testing the system, providing the required power for the loads, charging and discharging the batteries and the effect of the super capacitor in the system and making sure that it works properly and all problems (transient, harmonics, ripples, difference in response time for integrated components (Synchronization)) that faced in this work were completely solved.
From the literature review there are main problems, first part which is (how to enhance the overall performance of the PV power system using an effective MPPT technology?). Therefore, this work uses a suitable combination of various intelligent techniques, such as the FLC and ANN predictive (regression) and comparison with FLC and the conventional (P\&O) technique. To verify the efficiency of different MPPT algorithms at various external requested weather conditions for the designed system. Second part as for the reasons for choosing the DFIG, because it has advantages. The most important of these features, using DFIG is controlling (25$30) \%$ of the total power of power electronics converters, which is reducing the cost of these converters. As well as to enhance the performance of the ac mains network and its power factor (p.f.). The voltage and frequency of the stator windings are constant regardless of the speed change of the wind turbine. Finally, modeling and simulation of all renewable energy sources, with its controller in the MATLAB program. For testing the system, providing the required power for the loads, charging and discharging the batteries and the effect of the super capacitor in the system and making sure that it works properly and all problems (transient, harmonics, ripples, difference in response time for integrated components (Synchronization)) that faced in this work were completely solved.

\section{Main system configuration}

The system consists of several energy sources as shown as in Fig 2.1

1) Photovoltaic panels (PV's) with dc-dc boost converters.

2) Two DFIG based on wind turbines utilized SUT. The (DFIG) consists of two back-to-back PWM inverters connected between the stator and the rotor in the $\mathrm{AC}$ bus with drive controller .

3) Hybrid storage energy unit (HSEU) including batteries with chargers and Supper Capacitors with chargers. Battery and super capacitor chargers DC to DC bidirectional converters connected to the DC bus.

4) DC to DC boost converters connected to the solar panels groups by DC capacitor with its controller.

5) Inverters and DC capacitors. The inverters connected in parallel with their controllers. Therefore, the output from every inverter is a threephase voltage source of $500 \mathrm{~V}, 50 \mathrm{~Hz}$ frequency. These inverters are synchronized, together and then connected to three 3-Phase $\square / \square$ transformers with tap changer connected to the AC bus. There is a low pass LC-filter connected at the output of each inverter. The LC-filters are used to eliminate the harmonics in the current and voltage resulting due to the frequent work of inverter switches and the high power that is transferred to the loads. The high frequencies are eliminated and passage of the 
fundamental frequency. As well as the elimination of ripples and high rises at the output voltage, obtaining constant output voltage and frequency feed the required loads. Thus obtaining stable efficient and reliable power quality system.

6) The diesel generator is a standby

7) Most of those sources are connected to the DC or $\mathrm{AC}$ bus via power electronics devices and low pass filter. All energy sources are connected through transformers to the load except the diesel generator. Three of the 3-phase $\square / \square$ transformers with tap changer of input rang $(260-500 \mathrm{~V} / 600 \mathrm{~V})$, and power is $333.5 \mathrm{~kW}$ connected between the low pass filter (LC) and AC bus. The other two 3-phase $\Delta / Y$ transformers with tap changers of input rang (260$600 \mathrm{~V} / 600 \mathrm{~V})$ connected at the output of each DFIG and the AC bus. The transformer's tap changer is considered one of the most important parts in the transformer to maintain the output voltage of the bus.

The main system block diagram representing the daily AL-Mahmoudiya hospital loads according to the load demand is shown in Fig.2.1 The HRESS can be practically implemented with all design details. The equivalent simulation circuit for the practically implemented circuit, which is tested in a MATLAB/Simulink software. The design, simulation and control is performed for each energy source that has a special controller, as shown in Fig.3.17. The load calculations and sizing calculations for HRESS proposed in the paper were calculated.

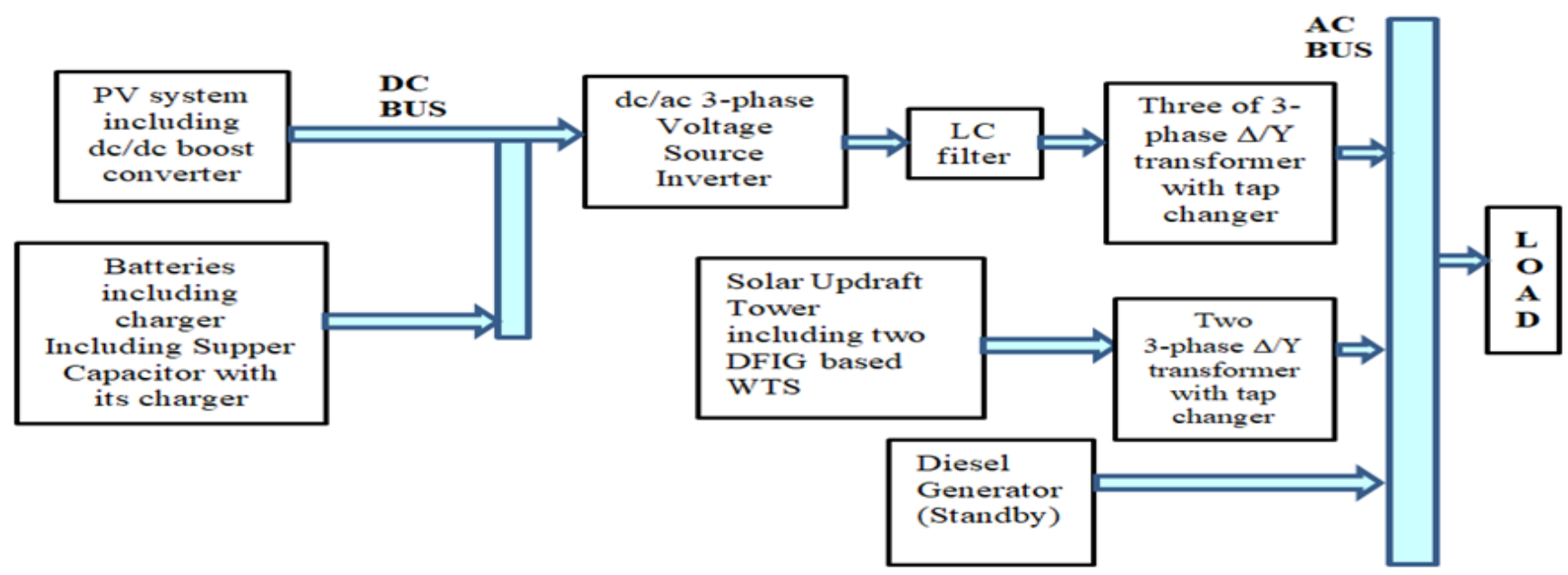

Fig.2.1. Main system block diagram.

\section{PV POWER SYSTEM}

In the PV system, harvesting the maximum output power of the PV array using maximum power point tracking (MPPT) is a very significant aspect. By which, under specific operation and conditions variation (load, ambient temperature, Solar irradiance), maximum power can be extracted from the PV panels. The primary goal of using the MPPT is to ensure that the PV panel operates at the most effective operating voltage (Vmp). The power generated from photovoltaic (PV) panels depend on Sun irradiance and ambient temperature. For this reason, despite variations in climatic conditions, the use of the MPPT is necessary to gain as much of the system's generating capacity as possible. The required total power of the PV system divided by the PV power of the panel equal number of panels needed for the design
These panels are organized in 14 arrays, each array linked in parallel as 66 strings, each string consisting of 4 panels linked in series. As shown in Fig.3.1 below.

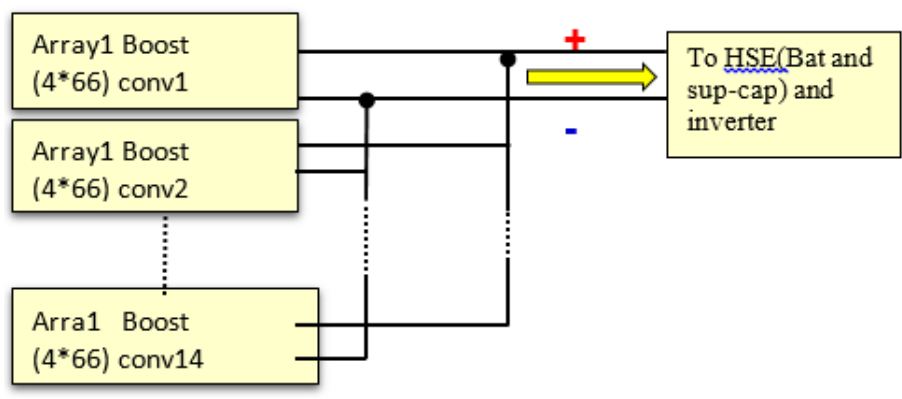

Fig.3.1 The PV Power System Array Connection

The method has been applied to control the boost converter to extract the maximum power. The first method applied in case of changing the solar irradiance or the temperature or 
both on 14 groups of the solar panel systems, each group connected to a boost converter. In this case, the control will keep the voltage constant at the input of the boost for the value of irradiance and the temperature, due to the change of the duty cycle, which led to the change of the voltage of the boost output through Neuro-fuzzy system. It predicts the greatest voltage $(\mathrm{Vm})$ of the solar panels when changing the solar irradiance and temperature. Thus gives an order to the duty cycle to control the boost converter, where the voltage at the output of the boost converter is variable at each solar irradiance and temperature. In addition, it is to control the output voltage of the boost converter since the duty cycle must be controlled. So if the output voltage is less than the required value of $500 \mathrm{~V}$, the Duty Cycle value will be increased. This is done by using a PI controller that compares the required voltage with the voltage coming from the controlling system. On the basis of the comparison, the Duty Cycle value is given to the threshold switch to control the boost converter and obtain a constant voltage. As shown in Fig.3.2 the Neuro-fuzzy system is accurate, reliable, and efficient, especially when used in such non-linear applications

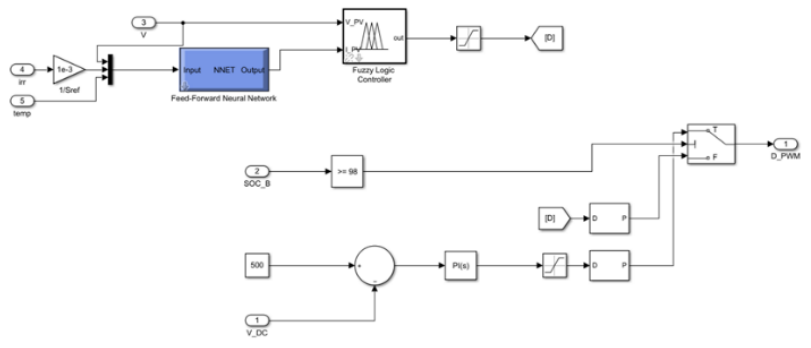

Fig.3.2 The Simulink of using the proposed Neuro-Fuzzy control for gives the regulated values of the Duty Cycle, which remains the output voltage of the boost (DC voltage) is constant.

\subsection{Design and Simulation of the proposed system (Neuro-Fuzzy) MPPT Controller}

The variation between the temperature and solar irradiance causes the greatest variable voltage of the solar panels. At any solar irradiance and temperature, the control system fixes the output voltage. As the output voltage is increased by the boost converter's control, and because of the difference in the duty ratio, the boost converter's output voltage is changed to get the greatest power at each output voltage. As for the current of the solar panels change at the inlet and outlet of the converter, due to the change of the solar irradiance to obtained maximum power. The proposed MPPT controller is designed to stabilize and track the optimum and maximum voltage for the PV arrays (Vmpp) produced by a trained ANN. Utilizing FLC to control PV arrays voltage, and regulate the $\mathrm{PV}$ voltage, to obtained maximum power. The method of prediction (regression) was used in the ANN, where the required value of the system is calculated theoretically. The voltage of the solar panels ( $\mathrm{Vpv}$ ) after the use of the solar panels of the same inputs data, that were used in the training of the ANN, and that the value of the (Vpv) is a target of the network to be trained. The ANN is trained with the use of the algorithm until the network output approaches the target, which was obtained from modeling a particular inputs range between training sets as shown in Fig.3.3. For the proposed controller, the measured or rated continuous solar irradiance $(\mathrm{G})$, temperature $(\mathrm{T})$, and PV arrays voltage Vpv. These values are used in predictive ANN training to control the transmission of greatest power to the load. The Neuro-Fuzzy controller design includes the design and train a predictive ANN and design a FLC.

\subsection{Design and Simulation of the proposed system (Neuro-Fuzzy) MPPT Controller}

The variation between the temperature and solar irradiance causes the greatest variable voltage of the solar panels. At any solar irradiance and temperature, the control system fixes the output voltage. As the output voltage is increased by the boost converter's control, and because of the difference in the duty ratio, the boost converter's output voltage is changed to get the greatest power at each output voltage. As for the current of the solar panels change at the inlet and outlet of the converter, due to the change of the solar irradiance to obtained maximum power. The proposed MPPT controller is designed to stabilize and track the optimum and maximum voltage for the PV arrays (Vmpp) produced by a trained ANN. Utilizing FLC to control PV arrays voltage, and regulate the PV voltage, to obtained maximum power. The method of prediction (regression) was used in the ANN, where the required value of the system is calculated theoretically. The voltage of the solar panels ( Vpv) after the use of the solar panels of the same inputs data, that were used in the training of the ANN, and that the value of the (Vpv) is a target of the network to be trained. The ANN is trained with the use of the algorithm until the network output approaches the target, which was obtained from modeling a particular inputs range between training sets as shown in Fig.3.3. For the proposed controller, the measured or rated continuous solar irradiance $(\mathrm{G})$, temperature $(\mathrm{T})$, and PV arrays voltage Vpv. These values are used in predictive ANN training to control the transmission of greatest power to the load. The Neuro-Fuzzy controller design includes the design and train a predictive ANN and design a FLC.

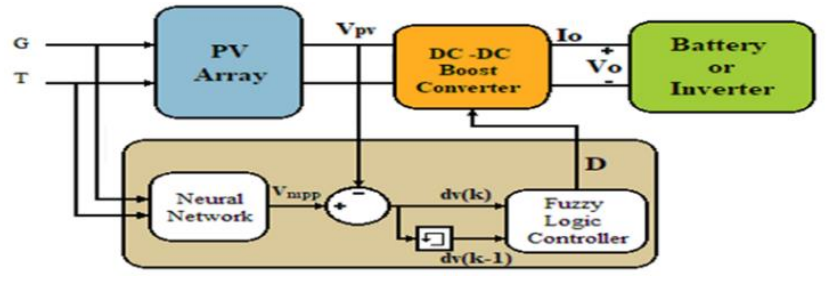

Fig.3.3 Neuro-Fuzzy controller

$\mathrm{dv}(\mathrm{k})=\mathrm{Vmpp}(\mathrm{k})-\mathrm{Vpv}(\mathrm{k})$

$\mathrm{D}(\mathrm{k})=\mathrm{D}(\mathrm{k}-1)+\mathrm{dD}(\mathrm{k})$ 
The ANN controller design. A statistical construct typically used to construct dynamic interactions between inputs and outputs in nonlinear systems is the predictive artificial neural network (ANN). ANN can also be defined as a parallel structure for the processing of distributed information. Inputs, at least one hidden layer, and one output layer consist of the ANN. Such layers have processing elements that are called neurons interconnected together. Used a supervised training algorithm with back propagation. The Levenberg Marquardt training algorithm (LM) trains the network LM the optimization algorithm (Training function) is commonly used to adjust the neuron weight by calculating the loss function gradient, which is a faster and better way to train and find the least possible error. This method is also called an error of back propagation. This is because the error in the output is calculated and circulated back through the layers of the network. In the paper, the inputs are two neurons, temperature (T) and irradiance (Gsi) are connected to both the neurons of the hidden layer. The second layer is considered the hidden layer, it is designed to have 10 neurons, where the previous layer's outputs act as the layer's inputs. A tensing activation function is used in the third layer is where the previous layer data is interpreted, the neuron of each hidden layer is connected by a weighted connection to the output layer neuron. Every weight is modified via the ANN training method to understand the nonlinear relationship between two training data signals inputs and the single output, and the output is generated using a linear pure line function is the optimum voltage (VMPP) output has one neurons, as shown in Fig.3.4, Fig.3.5, Fig.3.6 and Fig.3.7.

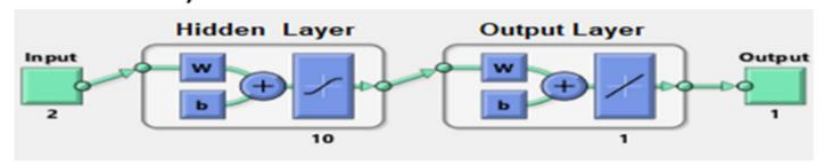

Fig.3.4 The Artificial Neural Network layers.

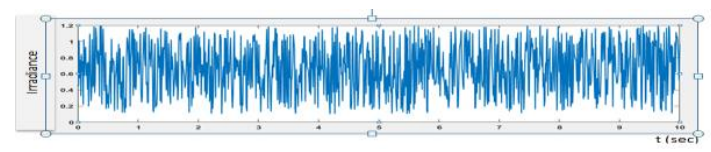

Fig.3.5 The irradiance input used for training the ANN.

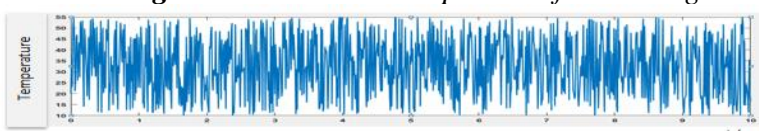

Fig.3.6 The temperature used for training the ANN.

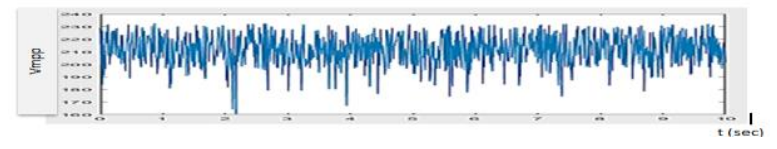

Fig.3.7 The estimated optimal output voltage (Vmpp) used for training the ANN.

Mean Square Error (MSE) is ANN error indicator. The role of learning is taken as trainlm. (Trainlm) is a network training feature that. The supervisor-learning algorithm with back propagation. Levenberg-Marquardt (LM) training optimization, updates weight and bias values. One of the most widely used algorithms is LM, which is a type of technique for numerical optimization. The MATLAB (newff) procedure is used to describe the training signals, their ranges, the number of neurons in each layer, and also to determine the neurons' activation function in each layer. By using a back propagation algorithm, the weights of the ANN are modified. The number of iterations used for testing is 300 , and the mean square error of 10-4 was used for the training phase stopping criterion (between the expected and the real output). The following training parameters were used during the ANN training stage, and the MATLAB measures shown below describe them:

$\operatorname{Ptr}=[\mathrm{G} ; \mathrm{T}], \mathrm{Vtr}=[\mathrm{Vmpp}]$

Net $=$ newff $([0.1 \quad 1.1 ; 10 \quad 55],[10 \quad 1],\{$ 'tansig' 'purelin'\},'trainlm').

Net.trainParam .epochs $=300$. Net.trainParam.goal $=0.0001$. Net $=$ train (net,Ptr,Vtr).Genism (net).Neural Network Training Regression (plot Regression) epoch 300. The best training performance of the designed ANN is depicted in Fig.3.8.

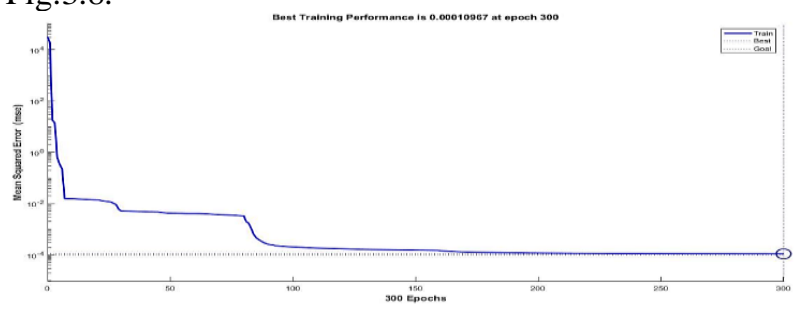

Fig.3.8 Best training performance of the designed ANN.

The exact values of solar irradiance and temperature readings are shown in Fig.3.9 in the Al-Mahmoudiya Hospital area on October 4, 2019. Such hourly data is then used to determine the accuracy of the ANN.

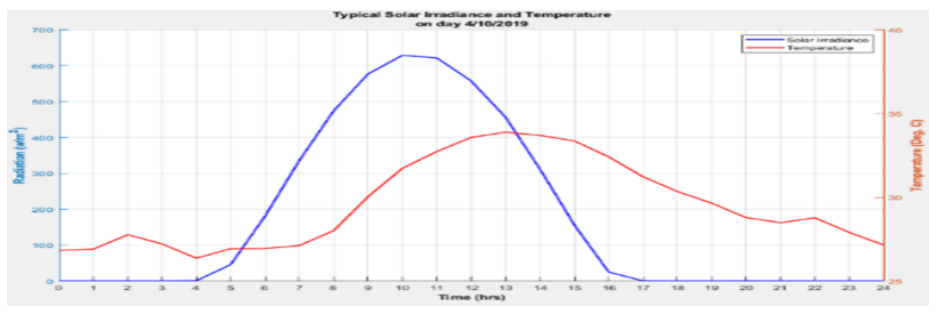

Fig.3.9 The measured values of solar irradiance $(0-700) \mathrm{W} / \mathrm{m}^{2}$ and temperature (15-35) $C$ on the 4th of October in 2019 at AlMahmoudiya Hospital area.

The ANN used the predictive method to increase accuracy and reliability in predicting the powers of the system under changing conditions, which is the basis of FLC, to make it quick to give the decision and the control of the maximum powers of the system. According to the design FLC. The membership function of two inputs of fuzzy logic controller. Triangular and bell shape Gaussian membership functions were used for the fuzzification process for the inputs $\operatorname{dv}(\mathrm{k})$ and $d v(k-1)$ and the output dD. As shown in Fig3.10. 


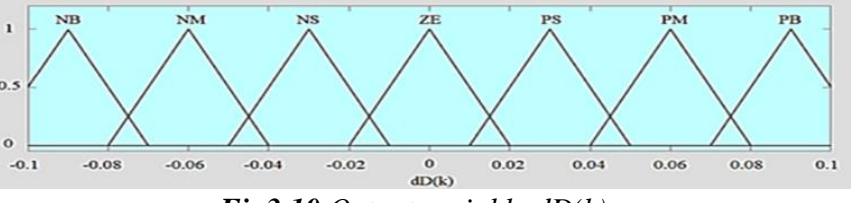

Fig3.10 Output variable $d D(k)$.

The inference engine used Mandeni's fuzzy inference approach. As shown in Table 3.1, the 49 rules were used to test the relationship between inputs and the output of the controller. The inference technique determines the output of the FLC. Mamdani's inference system is used alongside the max-min method. This is because this system is computationally more efficient and has good properties that are better than other suggestion-based techniques. The FLC output goes to the PWM generator which produces the reference voltage for the boost converter.

Table 3.1 Rules Base of The Fuzzy Logic Controller that used in the (Neuro-Fuzzy) system.

\begin{tabular}{|c|c|c|c|c|c|c|c|c|}
\hline & \multicolumn{7}{|c|}{$\operatorname{dv}(k-1)$} \\
\hline & & PB & $\mathbf{P M}$ & PS & ZE & NS & NM & NB \\
\hline \multirow{7}{*}{$\operatorname{dv}(k)$} & PB & PB & PB & PB & $\mathbf{P M}$ & $\mathbf{P M}$ & PS & $\mathrm{ZE}$ \\
\hline & $\mathbf{P M}$ & PB & PB & $\mathbf{P M}$ & $\mathbf{P M}$ & PS & $Z E$ & $\mathrm{NS}$ \\
\hline & PS & PB & $\mathbf{P M}$ & $\mathbf{P M}$ & PS & ZE & NS & $\mathrm{NM}$ \\
\hline & ZE & $\mathbf{P M}$ & $\mathbf{P M}$ & PS & ZE & NS & NM & $\mathrm{NM}$ \\
\hline & NS & $\mathbf{P M}$ & PS & $\mathrm{ZE}$ & NS & NM & NM & NB \\
\hline & NM & PS & $Z E$ & NS & NM & $\mathrm{NM}$ & NB & $\mathrm{NB}$ \\
\hline & NB & ZE & NS & NM & NM & NB & NB & $\mathrm{NB}$ \\
\hline
\end{tabular}

For the simulation of the operation of the whole designed system, including that of the PV array power system, boost converters and the proposed Neuro-Fuzzy controller, the Simulink model shown in Fig.3.11

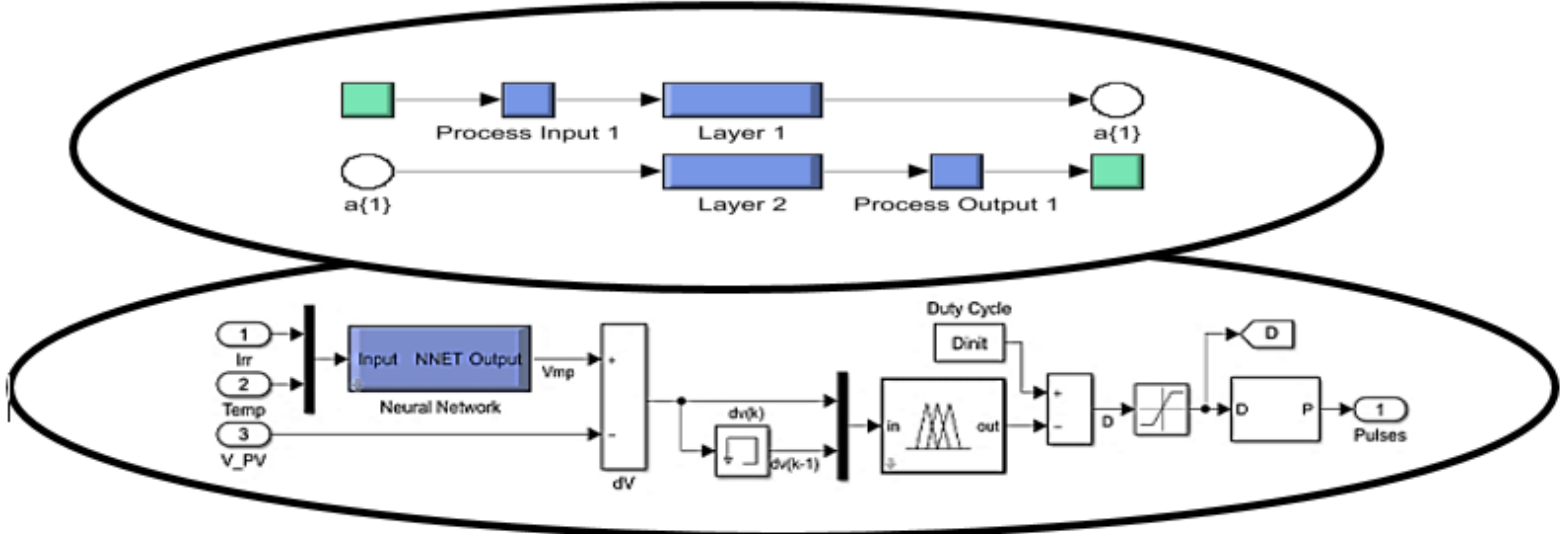

Fig.3.11 Simulink Model subsystem Neuro-Fuzzy controller.

3.2 Simulation and Control of Double fed induction generator-based Wind Turbine (Second part of proposed the system)

The double fed induction generator has been simulated and controlled by (AC/DC/AC) converter using MATLAB/ Simulink during stable state. The Control and simulation have been done for one model of generators of $300 \mathrm{~kW}$ and turbine as shown in Fig.3.12.

Although the turbine is configured in compliance with the generator's nominal power, the DFIG function is based on the vector control of the rotor voltages of the unit utilizing the PI form. The sampling period is ( $5 \mu$ second, at this time, the signal appears clear and MATLAB will not run late). 


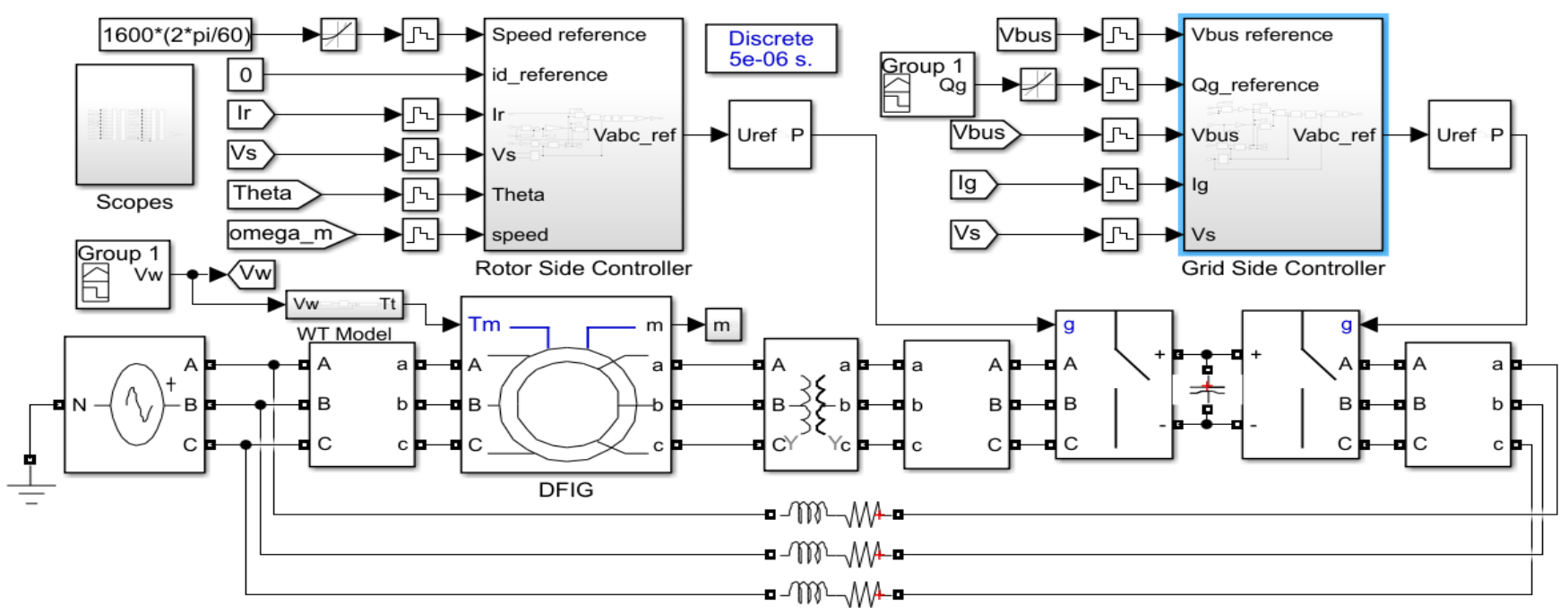

Fig.3.12 Schematic Diagram of DFIG Based Wind Turbine in MATLAB/Simulink

3.2 Simulation and Control of Double fed induction generator based Wind Turbine (Second part of proposed the system)

The double fed induction generator has been simulated and controlled by (AC/DC/AC) converter using MATLAB/ Simulink during stable state. The Control and simulation have been done for one model of generators of $300 \mathrm{~kW}$ and turbine as shown in Fig.3.12.

Although the turbine is configured in compliance with the generator's nominal power, the DFIG function is based on the vector control of the rotor voltages of the unit utilizing the PI form. The sampling period is ( $5 \mu$ second, at this time, the signal appears clear and MATLAB will not run late).

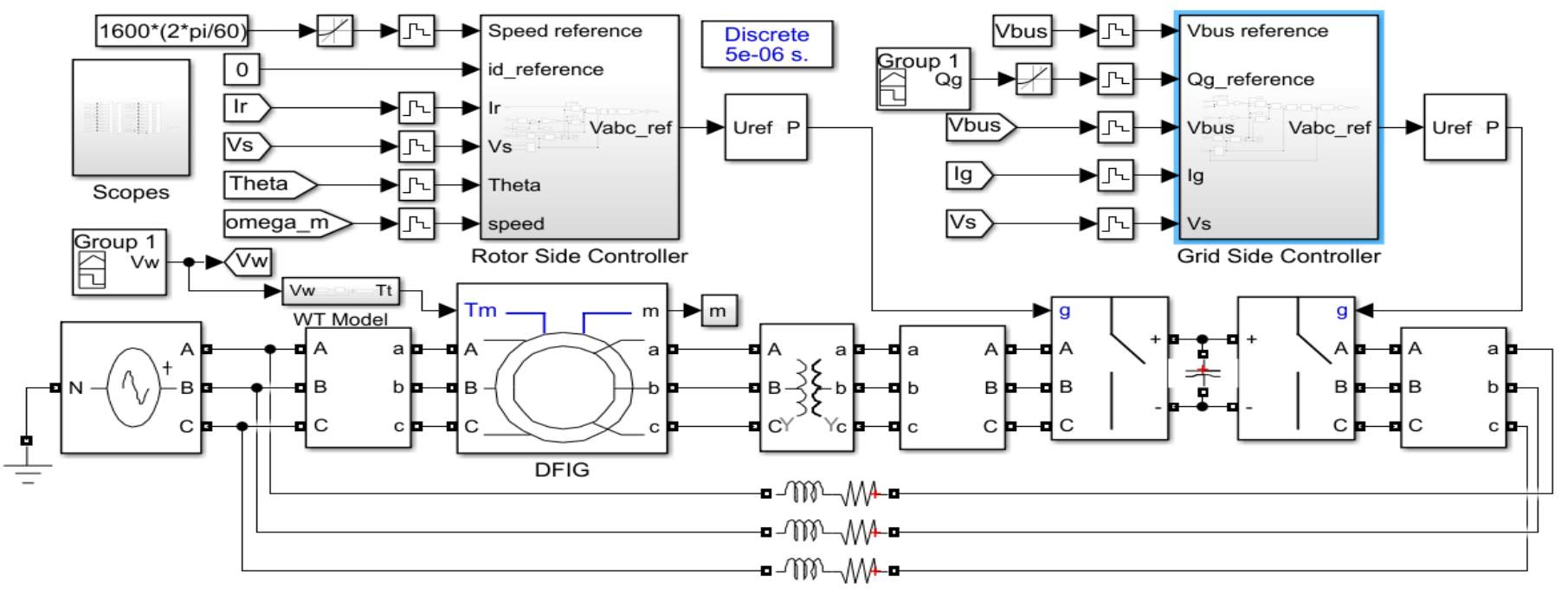

Fig.3.12 Schematic Diagram of DFIG Based Wind Turbine in MATLAB/Simulink

\subsubsection{Control of rotor side convertor in MATLAB/ Simulation}

An important part of the electrical machine is the rotor side (RSC) of the generator. As shown in Fig.3.13, the schematic diagram of (RSC) in MATLAB / Simulink. This includes two motions, mechanical movement and electrical movement, both of which affects the machine's operating model. As a product of its behavior and its characteristics. When operated in sub synchronous mode, synchronous mode and synchronous supper mode, during our work using
MATLAB/ Simulink for wind energy control system using DFIG to get maximum power with constant output voltage magnitude and frequency. It will control the frequency of the rotor's flux. DFIG is controlled by the vector control technology of the PI regulator, controlling the rotor windings currents to provide suitable voltages injected into the rotor windings of the machine. Details of these equations are shown in $[9,10,11]$. It is provided (MPPT) by using indirect speed control in the turbine to extract the maximum power according to the appropriate wind speed. It gives the optimum electromagnetic torque, and thus gives 
the required current (Iqr). In the event of a different work speed, the measured current (Iqr) is controlled by PI, where it corrects the error. When the current (Idr) is zero according to the control strategies, this means that the generator is consuming reactive power (Qs), it is not controlled. In the practical circuit, two DFIG are connected, each generator give a power of $300 \mathrm{~kW}$ and are connected with the tap changer transformer to give a constant output voltage, in the event of sudden changes to the system. As for the equivalent circuit that was simulated with MATLAB, one equivalent DFIG is connected instead of the two and gives a power of $600 \mathrm{~kW}$ equivalent to the power of the two generators.

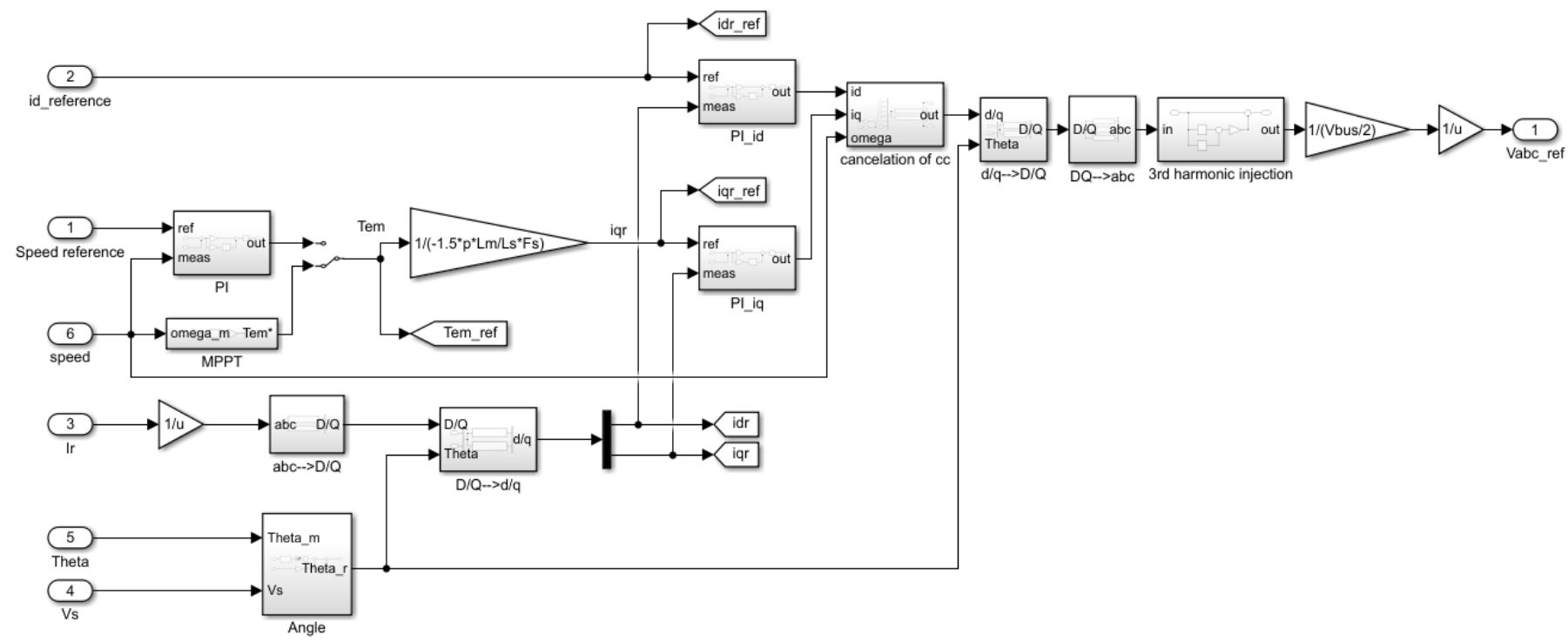

Fig.3.13 Block diagram of (RSC) and MPPT control strategy.

\subsection{Hybrid Energy Storage System and Control System.}

A battery and super capacitor bank compose the planned active hybrid energy storage system. Via two DC/ DC bidirectional power converters, the functions of the super capacitors are;

First case, in the event of a transient, it is absorbed by the super capacitors, and it is considered a charge for (SC). This is because the super capacitors are by two operations of fast charging and discharging. It should be able to absorb the ripples or high-frequency power component. Second case, if the batteries are discharged feeding the required loads. Initially and only for a short period, the super capacitor enters the discharge process, and after that, it is disconnected from service and its current will be combined with the battery current to reduce the intensity of the batteries' discharge current. Because the batteries lose their power during the discharge stage, as well as when the batteries while supplying the loads reach the protection ratio of $30 \%$. In case, loads need more power and the batteries loses $70 \%$ from its capacity, the super capacitor enter the service to supply the load for a limited time, ranges from seconds to hours, and in this way, the battery life is preserved. The energy sharing between the batteries and the supper capacitors can be controlled by regulating the converters located between the energy storage devices and the DC bus voltage. The state of charged batteries is taken with the transient case. First comparison between measured DC bus voltage $(\mathrm{Vdc})$ from mains source and reference DC voltage $(\mathrm{Vdc} *=500 \mathrm{~V})$. If the measured DC bus voltage $(\mathrm{Vdc})$ is greater than the DC reference voltage $(\mathrm{Vdc} *=$ $500 \mathrm{~V})$, then the output from the PI1 controller is the reference current (Iref). It is inserted into the filter for the purpose of getting rid of the ripple. The reference current will be reference current of the batteries (I-Bat*). When using the second comparator, the error e 2 is negative, with PI2 controller the batteries should be charged.

And the error e 3 is negative resulting from the third comparator, so the error $\mathrm{e} 4$ is negative resulting from the fourth comparator. It was multiplied with the ratio, which is the ratio of the batteries' voltage (VBat) to the voltage of the supper capacitor (Vsc). If the ratio is less than one, the batteries will be charged. But if the ratio is greater than one, then the supper capacitor is charged. Whereas the fifth comparator and the PI 3 controller are used, and on this basis the super capacitors is charged, and the comparison processes occur at every moment. The second case occurs when changing solar irradiance reduced from 1000 to 400 $\mathrm{W} / \mathrm{m}^{2}$. At a certain moment the batteries sensed that are discharging, the super capacitor will also discharge, but it soon becomes apparent that, there is excess power from the sources that are being used to charge the batteries, as shown in Fig.3.14. 


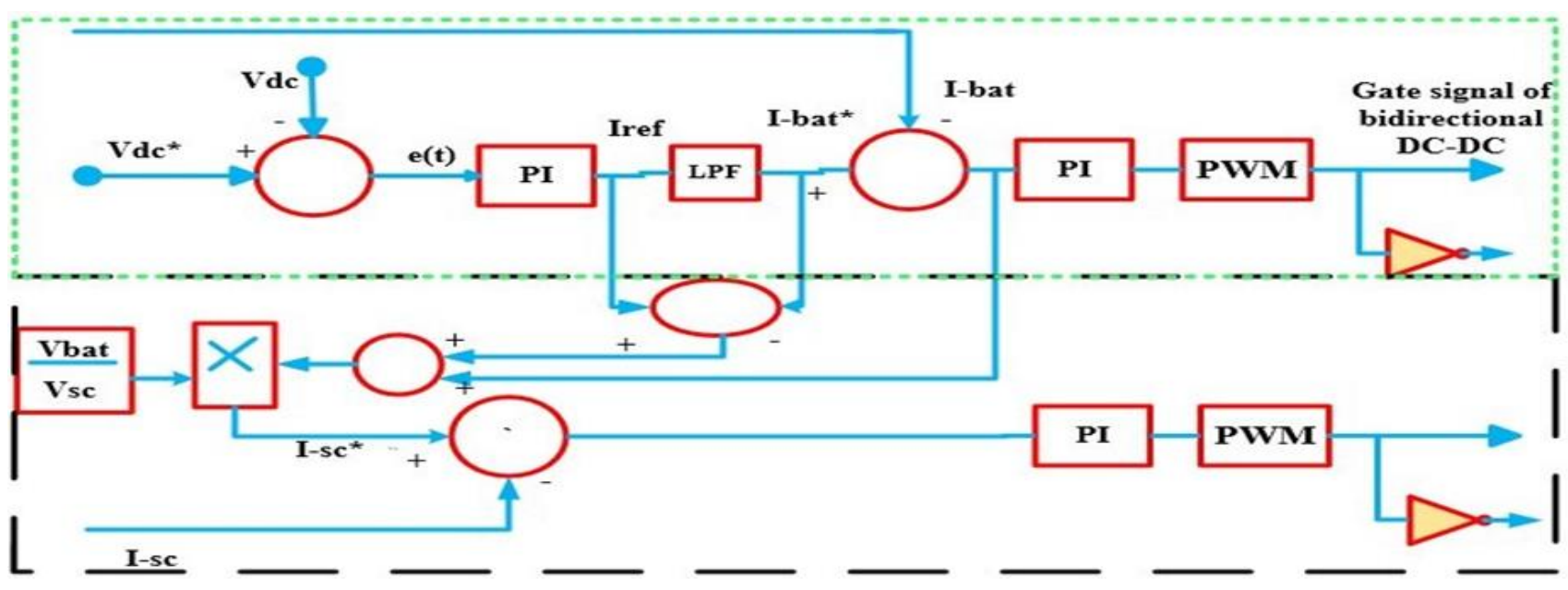

Fig.3.14. a Block diagram of the control system implemented in MATLAB for the HSS.

The equivalent simulation circuit for the practically implemented circuit as shown in Fig.3.15, which is tested in a MATLAB/Simulink software. The design, simulation and control is performed for each energy source that has a special
controller.And observing the effect of super capacitors when connected to the system, and the effect of the power source control system on the response and operation of super capacitors

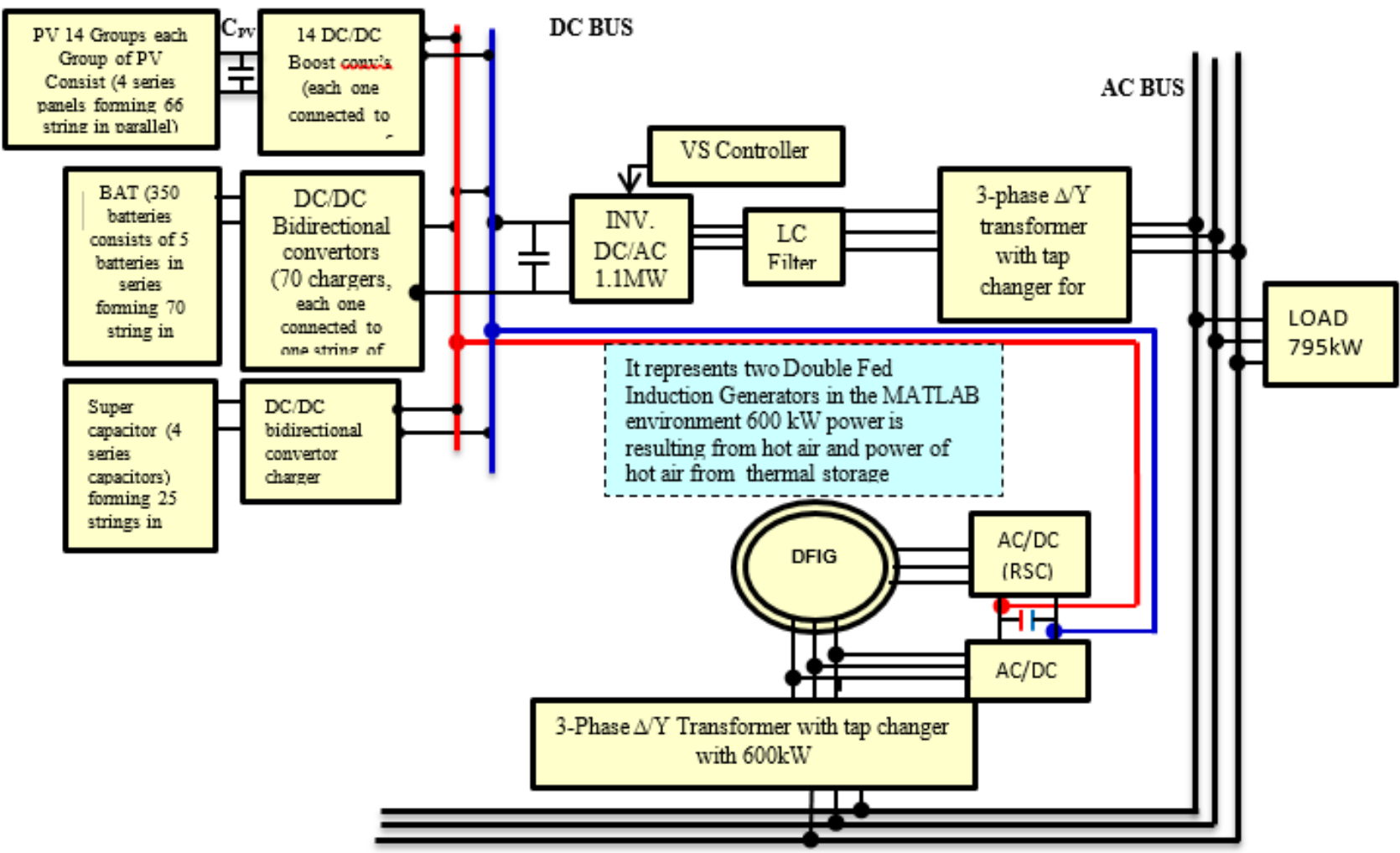

Fig.3.15 The equivalent simulation circuit proposed using MATLAB/Simulink

\subsection{Simulation tests for the complete HRESS under variable conditions}

All renewable energy sources as shown in Fig.3.16, which include 14 groups of solar panels with 14 boost converters, the equivalent DFIG with back to back PWM inverter with the equivalent tap changer transformers, with the storage energy system, and the equivalent inverter, and its accessories. The equivalent filter is included with the tap changer transformer that have been connected, tested, implemented and simulated in the MATLAB program. The system is controlled for each source with all parts and requirements for connection under various conditions were used. This is to ensure that they work properly to obtain DC 
and $\mathrm{AC}$ voltages, currents and powers to feed the loads. Required where the system must be available, reliable, stable and of good quality power. The system is clarified, tested and implemented in general and not at a specific time of the day. The control strategy applied to the hybrid system as follows:

a. The first case of control is the implementation using the Fuzzy control on the groups of the solar panel system, to obtain the maximum power. Then loads, in this case, are $800 \mathrm{~kW}$ under solar irradiance (1000- 400- 700) W/m². The response of the batteries when solar irradiance is $1000 \mathrm{~W} / \mathrm{m}^{2}$ remaining from the excess of power are approximately $800 \mathrm{~kW}$, after feeding the loads from the sources is charged and stored in the batteries. In the case of solar irradiance $400 \mathrm{~W} / \mathrm{m}^{2}$, noticing the response of the batteries to discharge process from the previous case, but it soon becomes clear that it is the remaining power approximately is $260 \mathrm{~kW}$ in solar irradiance $400 \mathrm{~W} / \mathrm{m}^{2}$, after feeding the loads by the sources to store energy in the batteries. The super capacitor, noticing its response to the phenomenon of transient since the state of transient can be likened to the increased power of the system that is charged and stored. In the event that the batteries are discharged at the start, the super capacitor is discharged with batteries to reduce the discharge current of the batteries. This is because in the absence of super capacitor, so in this case, exposing the batteries to losing a quantity of their power. Thus it preserves the life of the batteries, but there are changes that occur in the system for a very short period due to the external conditions troubled where the intelligent control system of the PV panels dose this work and returns the system to a steadystate. It appears that the system has easy to implement, fast, and efficient response under various conditions. In this system that the waves (three phase alternating voltage, current and power) contain a little of a ripple, and that any change in the system parameters is a large error rate.

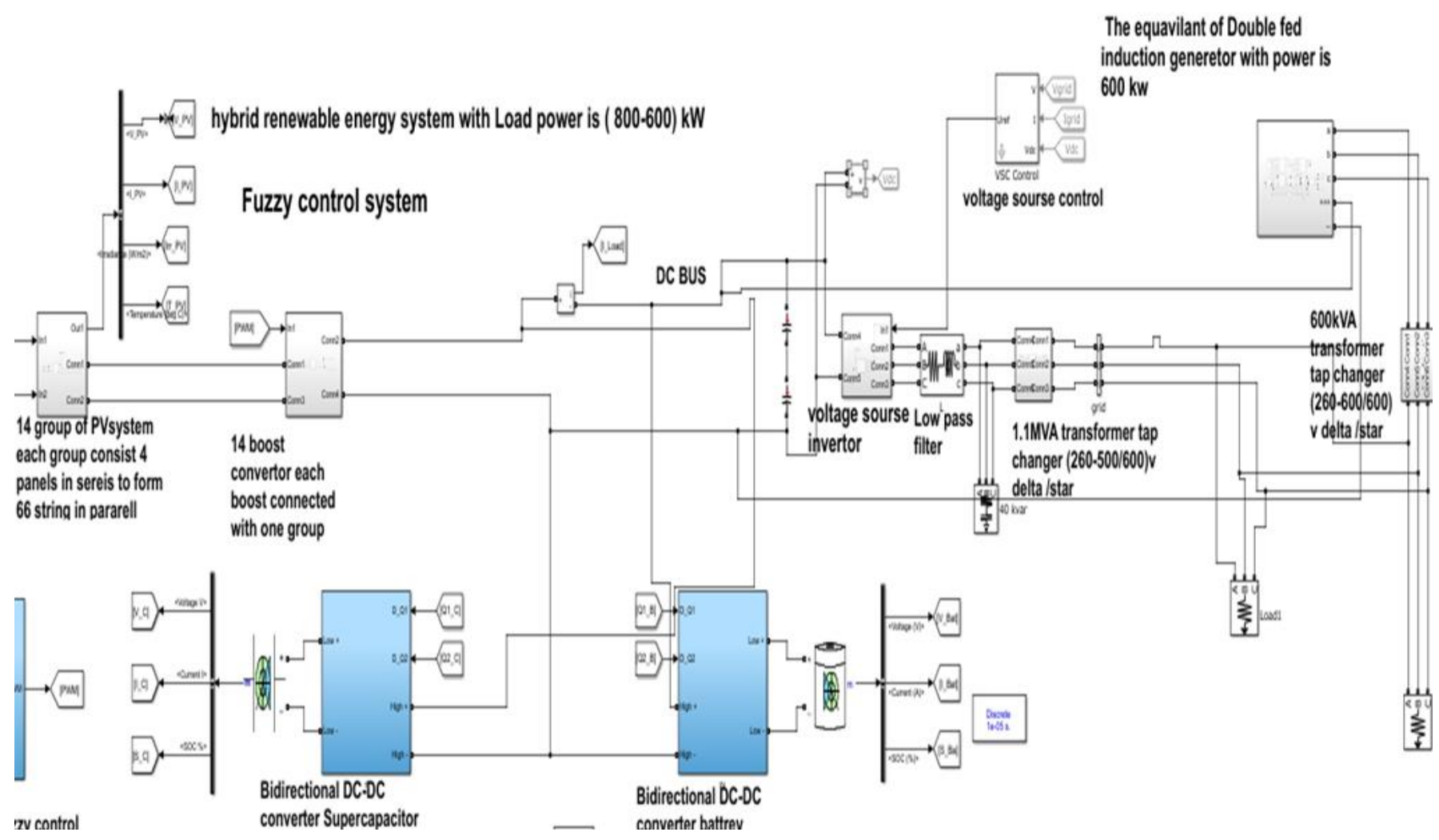

Fig.3.16 Simulation block diagram for the HRESS using MATLAB program.

b. The second case using the Neuro-Fuzzy system on the groups of solar panel system, to obtain the maximum power. Then the loads, in this case, are $800 \mathrm{~kW}$ and under solar irradiance (1000- 400- 700) $\mathrm{W} / \mathrm{m} 2$. The resulting power from renewable energy sources in terms of response raising time, stability, accuracy, ripples and oscillation. As well as the fast response of supper capacitors and the batteries when the solar irradiance is $1000-400 \mathrm{~W} / \mathrm{m} 2$ of the excess power, after feeding the loads from the sources. They are charged and stored energy in the batteries and the performance of super capacitors, the system is faster, more accurate more stable, more reliability, available, and the efficiency $98 \%$ is better than the previous system, as well as the good quick and accurate response to the power sources in the hybrid renewable energy system. And it works to improve the ripple in waves (three phase alternating voltage, 
current, power), and any changes that occur to the system can be avoided by the training process.

\section{THE TEST SIMULATION RESULTS FOR THE COMPLETE HRESS UNDER VARIABLE CONDITIONS WITH THE EFFECT Of SUPER CAPACITORS PERFORMANCE .}

The simulation result after connected the complete system, tested and implemented the renewable energies sources system with each other. They are consisting of 14 groups of solar panels connected with 14 boost converter with the equivalent DFIG of power of $600 \mathrm{~kW}$ to the hybrid storage system are shown. They are connected to the equivalent threephase inverter with its control system, which is connected to the equivalent filter with transformers have tap changers to supply the required loads. The drawings show the total power of all the sources and the power of the loads that were covered from the sources with the remaining power used to charge Batteries are for the winter days explained as shown in Figs 4.1.

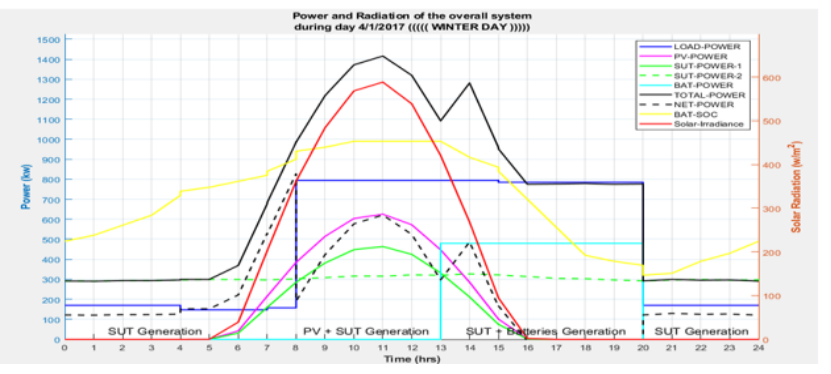

Fig.4.1 Solar irradiance and power sources during a winter day

The results of the total system powers, voltages and currents according to the following cases:

\section{a. Fuzzy control system:}

The first controller used in MATLAB software is the Fuzzy control system for the complete solar panels system connected to the total hybrid renewable energy system with the total load's power of $800 \mathrm{~kW}$. At the solar irradiance $1000 \mathrm{~W} / \mathrm{m}^{2}$, as the sources feed the load, so the remaining power is used to charge the batteries. In the case of solar irradiance $400 \mathrm{~W} / \mathrm{m}^{2}$, notice that the batteries are sensed when the irradiance is reduced to the state of discharge to feed the load. Still, it soon becomes clear that the remaining power of the system after feeding the load at this irradiance is used to charge the batteries. As for the case of solar irradiance $700 \mathrm{~W} / \mathrm{m}^{2}$, note the power of the sources, according to what was mentioned above. As for the transient that occurs, the super capacitors is working to energy storage and compensate for its power when needed, as shown in the Figures. 4.2 (a, b, c, d), 4.3, 4.4 $(a, b, c)$.

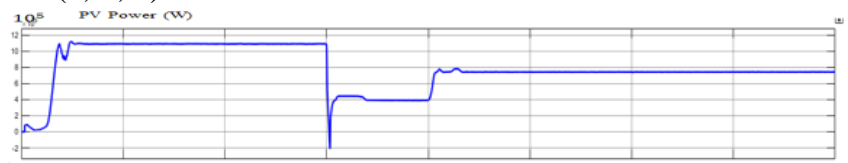

Fig.4.2.a The power of the PV system after boost converter

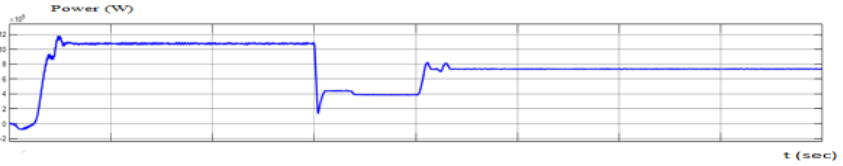

Fig.4.2.b The power before the inverter.

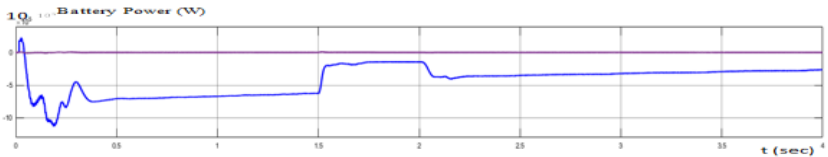

Fig.4.2.c The storage system power.

SC Power (W)

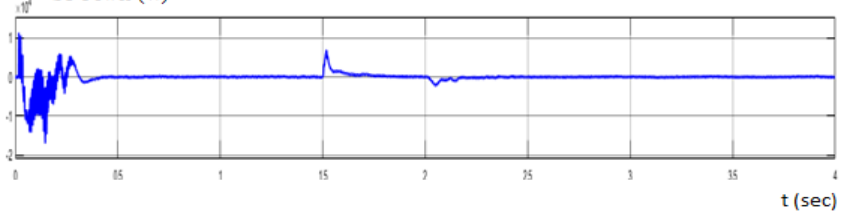

Fig.4.2.d The Power of the super capacitor.

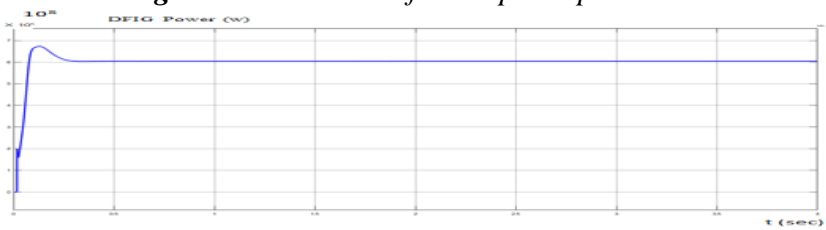

Fig.4.3 Simulation result of the equivalent power of DFIG.

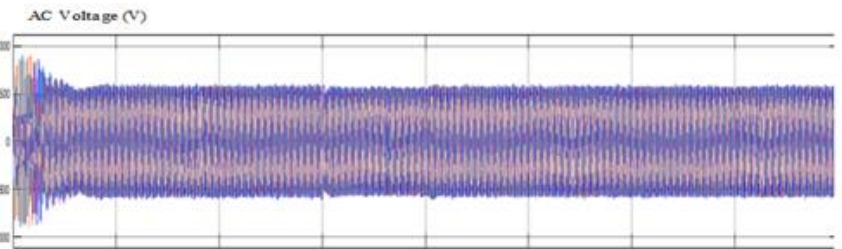

Fig.4.4.a The 3-phase AC output voltage of inverter.

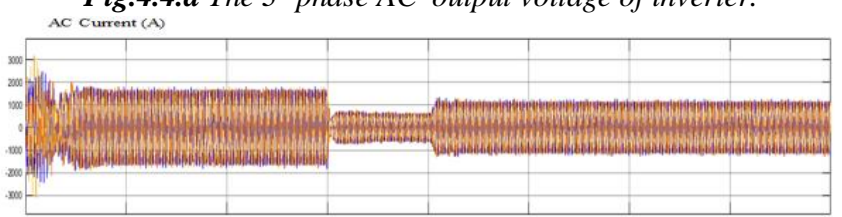

Fig.4.4.b The 3-phase AC output current of inverter

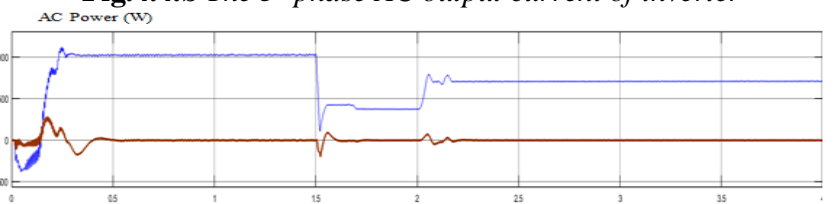

Fig.4.4.c The 3-phase AC output Power (RMS).

\section{b. Neuro-Fuzzy control system, load $800 \mathrm{~kW}$}

Noticing the results of power feeding the loads, output currents and voltages. As for the remaining power of the sources used to charge the batteries, notice when working 
with the Neuro-Fuzzy system, which led to improving the ripple at the output waveforms and a faster response to the surrounding changes. Clearly from the use of the Fuzzy control system alone and because it is an accurate, reliable and fast system. But the high neural response to any disturbances. In the event that a transient occurs in the system ANN works on rapid training and the system returns to steady- state with a short period of time. As for the Fuzzy, it will reduce the value of the transient. They function more smoothly, effectively and efficiency when put together than when used separately. Also, note accurate, few ripple and fast response to the power of the remaining from the two sources to use the storage batteries. As for the performance of the work of the super capacitors, it is much better and faster response than the control of the previous system, as shown in the figures.4.5 (a, b, c, d), 4.6 (a, b, c).

$10^{5} \quad$ PV Power (W)

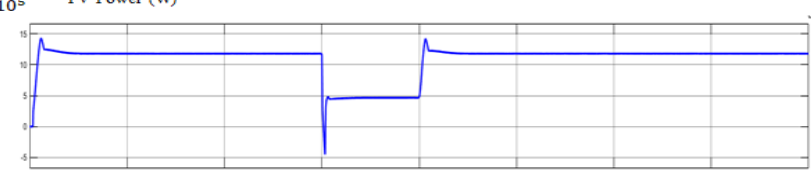

Fig.4.5.a The power of the PV system after boost converter. $10^{5} \quad$ Power $(\mathrm{W})$

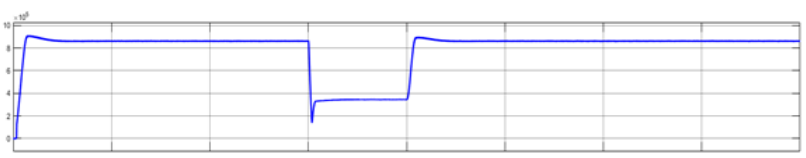

Fig.4.5.b The power before the inverter 10 Battery Power (W)

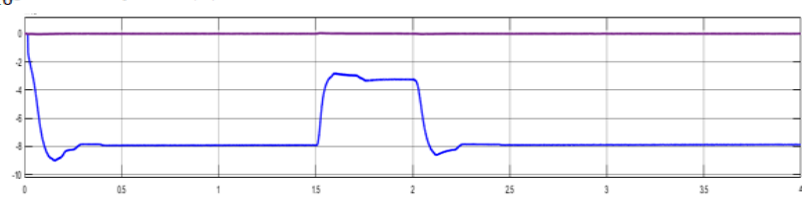

Fig.4.5.c The power storage of the battery

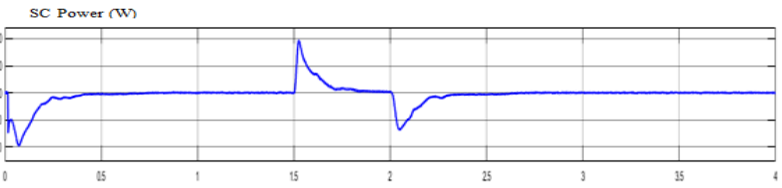

Fig.4. 5.d The Power of the super capacitor

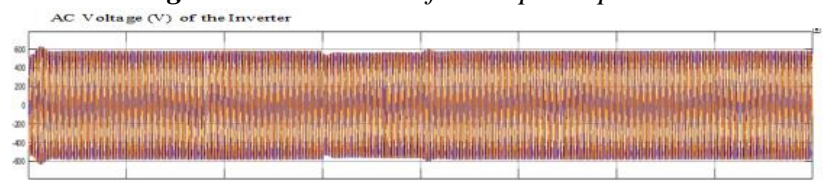

Fig.4.6.a The 3-phase AC output voltage from inverter.

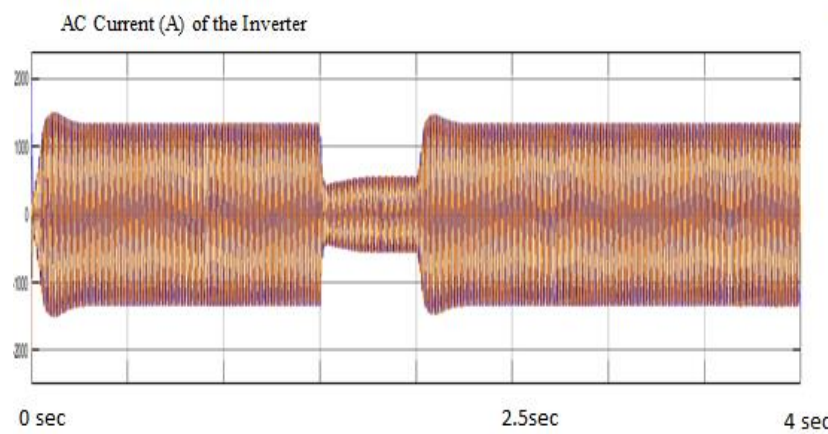

Fig.4.6.b The 3-phase AC output Current form inverter AC Power (W) of the Inverter

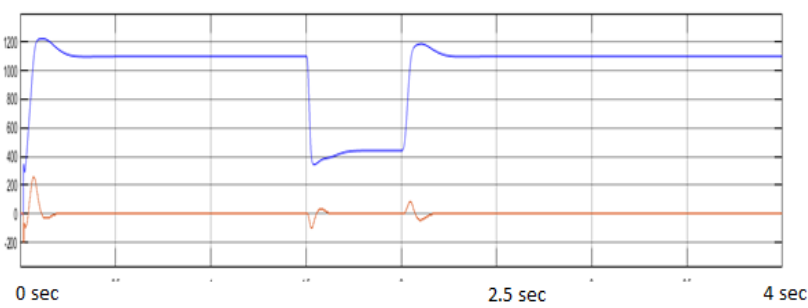

Fig.4.6.c The 3-phase AC output Power from inverter.

\section{CONCLUSION}

The HRESS are controlled to achieve a stable voltage with frequency, and extract the maximum energy to supply the required loads. Since all HRESS were connected, tested and implemented in MATLAB software. When working with the Fuzzy control system, and with the Neuro-Fuzzy control system on the solar panels system, connected to the hybrid renewable energy system under various weather conditions, and different load. when working with the Nero-Fuzzy system, which led to improving the ripple at the output waveforms $98 \%$ and faster response to the surrounding changes, and disturbances from the use of the FLC alone. This is because it is an accurate, reliable and fast system. The voltage and current waveforms coming out of the filter associated with the inverter are pure sine wave, as the ratio of the total harmonic distortion in both waveforms is less than the value of the IEEE standard. The results showed the effect of super capacitors performance on improving system performance and battery protection. The battery storage system could store more energy and supply constant load power for a longer period of time at a low expense. Consequently, the super capacitors decreased the current and voltage of the batteries about (25-30) \%, extended its longevity and eventually reduced the system's operation and repair costs.

\section{REFERENCES}

[1] Hamadi, M. R. A., Chandra, A., \& Singh, B. (2014). Hybrid AC-DC standalone system based on PV array and wind turbine. In IECON Proceedings (Industrial Electronics Conference) (pp. 5533-5539). Institute of Electrical and Electronics Engineers Inc. https://doi.org/10.1109/IECON.2014.7049346 
[2] Tang, X., Deng, W., \& Qi, Z. (2014). Investigation of the dynamic stability of microgrid. IEEE Transactions on Power Systems, 29(2), 698-706. https://doi.org/10.1109/TPWRS.2013.2285585

[3] Karabiber, A., Keles, C., Kaygusuz, A., \& Alagoz, B. B. (2013). An approach for the integration of renewable distributed generation in hybrid DC/AC microgrids. Renewable Energy, 52, 251-259. https://doi.org/10.1016/j.renene.2012.10.041

[4] Sumathi, S., Ashok Kumar, L., \& Surekha, P. (2015). Solar PV and Wind Energy Conversion Systems. Green Energy and Technology (p. 807). Retrieved from http://link.springer.com/10.1007/978-3-319-14941-7

[5] Tan, X., Li, Q., \& Wang, H. (2013). Advances and trends of energy storage technology in Microgrid. International Journal of Electrical Power and Energy Systems, 44(1), 179-191. https://doi.org/10.1016/j.ijepes.2012.07.015

[6] Hafizh, H., Shirata, H. (2015). Aerothermal simulation and power potential of a solar updraft power plant. Journal of structural Engineering. Vol.61A. http://dx.doi.org/10.11532/structcivil.61A.388

[7] Zhou, X., \& Xu, Y. (2016, April 1). Solar updraft tower power generation. Solar Energy. Elsevier Ltd. https://doi.org/10.1016/j.solener.2014.06.029

[8] Salman, A. D., Murtadha, T. K., \& Salih, H. M. (2020). Thermal Efficiency for Passive Solar Chimney with and Without Heat Storage material. Journal of Engineering, 26(5), 1-19. https://doi.org/10.31026/j.eng.2020.05.0

[9] Mendis, N., Muttaqi, K. M., \& Perera, S. (2012). Active power management of a super capacitor-battery hybrid energy storage system for standalone operation of DFIG based wind turbines. In Conference Record - IAS Annual Meeting (IEEE Industry Applications Society). https://doi.org/10.1109/IAS.2012.6374045

[10]Blaabjerg, F., Liserre, M., \& Ma, K. (2012). Power electronics converters for wind turbine systems. In IEEE Transactions on Industry Applications (Vol. 48, pp. 708-719). https://doi.org/10.1109/TIA.2011.2181290

[11] Kaloi, G. S., Wang, J., \& Baloch, M. H. (2016). Active and reactive power control of the doubly fed induction generator based on wind energy conversion system. Energy Reports, 2, 194-200. https://doi.org/10.1016/j.egyr.2016.08.001

[12] Schlaich, J., Bergermann, R., Schiel, W., \& Weinrebe, G. (2005). Design of commercial solar updraft tower systems Utilization of solar induced convective flows for power generation. Journal of Solar Energy Engineering, Transactions of the ASME, 127(1), 117-124. https://doi.org/10.1115/1.1823493

[13] Nordin, N. D., \& Abdul Rahman, H. (2016). A novel optimization method for designing stand alone photovoltaic system. Renewable Energy, 89, 706-715. https://doi.org/10.1016/j.renene.2015.12.001

[14] Suntio, T., \& Messo, T. (2019). Power electronics in renewable energy systems. Energies. MDPI AG. https://doi.org/10.3390/en12101852 